\title{
Origin and main branches of the cranial and caudal mesenteric arteries in the New Zealand rabbit
}

\author{
ESTRUC, T. M. ${ }^{1}$, NASCIMENTO, R. M. ${ }^{2}$, SISTON, N. M. ${ }^{3}$, \\ MENCALHA, R. ${ }^{4,5}$ AND ABIDU-FIGUEIREDO, M. ${ }^{6 *}$
}

\author{
${ }^{1}$ Autonomous: zootechnician \\ ${ }^{2}$ Post-graduation Program in Animal Biology, Federal Rural University of Rio de Janeiro - UFRRJ, \\ Rodovia BR 465, Km 7, CEP 23851-970, Seropédica, RJ, Brazil \\ ${ }^{3}$ Medical School, Estácio de Sá University, Rio de Janeiro, RJ, Brazil \\ ${ }^{4}$ Department of Surgery and Anesthesiology, Faculty of Veterinary Medicine, Valença Higher Education Center - \\ CESVA, Rua Sargento Vitor Hugo, 161, Fátima, CEP 27600-000, Valença, RJ, Brazil \\ ${ }^{5}$ Post-graduation Program in Veterinary Medicine, Federal Rural University of Rio de Janeiro - UFRRJ, \\ Rodovia BR 465, Km 7, CEP 23851-970, Seropédica, RJ, Brazil \\ ${ }^{6}$ Department of Animal Biology, Animal Anatomy Area, Federal Rural University of Rio de Janeiro - UFRRJ, \\ Rodovia BR 465, Km 7, CEP 23851-970, Seropédica, RJ, Brazil \\ *E-mail: marceloabidu@gmail.com
}

\begin{abstract}
Introduction: Precise knowledge of variations in arterial vascularization of the abdominal viscera is important for systematization of radiological and surgical anatomy in animals that serve as experimental models and in domestic animals. Objective: The aim of this study was to describe the origin and main branches of the cranial and caudal mesenteric arteries in rabbits. Materials and Methods: The anatomical dissections were performed in 30 cadavers of adult rabbits, 15 males and 15 females. Results: The cranial mesenteric artery arose as a single artery in all females and males. The average length of the cranial mesenteric artery in females was $2.63 \mathrm{~cm}$ and originated at the level of lst lumbar vertebra in two (13.33\%) animals, between the 1st and 2nd lumbar vertebra in four $(26.67 \%)$, on the 2 nd lumbar vertebra in seven $(46.67 \%)$, between 2 nd and 3rd lumbar vertebra in one $(6.67 \%)$ and at the level of $3 r d$ lumbar vertebra in one $(6.67 \%)$. The average length of the cranial mesenteric artery in males was $2.56 \mathrm{~cm}$ and originated at the level of lst lumbar vertebra in two (13.33\%) animals, between the 1 st and 2 nd lumbar vertebra in two (13.33\%), at the level of the 2 nd lumbar vertebra in eight $(53.33 \%)$, between the 2 nd and 3 rd lumbar vertebra in three (20\%). The main ramifications of the cranial mesenteric artery were the caudal pancreatic duodenal, middle colic, jejunal and ileocecocolic arteries. The caudal mesenteric artery arose as a single artery in all females and males. The average length of the caudal mesenteric artery in females was $0.846 \mathrm{~cm}$ and originated at the level of 5 th lumbar vertebra in three $(20 \%)$ animals, between the 5 th and 6th lumbar vertebra in two (13.33\%), at the level of the 6th lumbar vertebra in seven $(46.67 \%), \%)$, between the 6th and 7 th lumbar vertebra in two $(13.33 \%)$ and at the level of the 7 th lumbar vertebra in one $(6.67 \%)$. The average length of the caudal mesenteric artery in males was $0.79 \mathrm{~cm}$ and originated at the level of the 5 th lumbar vertebra in two $(13.33 \%)$ animals, between the 5 th and 6 th lumbar vertebra in one $(6.67 \%)$, at the level of the 6th lumbar vertebra in seven $(46.67 \%)$, between the 6 th and 7 th lumbar vertebra in four $(26.67 \%)$ and at the level of the 7 th lumbar vertebra in one $(6.67 \%)$. The caudal mesenteric artery arises from the aorta, originating the cranial rectal and left colic arteries. Conclusion: No relation was observed between the mesenteric length and the rostrum-sacral length in rabbits. The origin of the cranial and caudal mesenteric artery is not gender dependent.
\end{abstract}

Keywords: anatomy, mesenteric artery, rabbit (Oryctolagus cuniculus).

\section{Introduction}

The morphology of the digestive tract correlates well enough with the function so that the feeding habits and diets can be determined using the digestive system as a basis (GETTY, 1986; DYCE, SACK and WENSING, 2010; KÖNIG and LIEBICH, 2011).

Anatomically, rabbits' digestive tract is characterized by a simple glandular stomach, long intestinal tract and very large cecum. The rabbit cecum is functional and is responsible for promoting bacterial fermentation and vitamin $\mathrm{B}$ synthesis (AMORIM, AMORIM-JÚNIOR, SILVA-JÚNIOR et al., 2002).

Precise knowledge of variations in arterial vascularization of the abdominal viscera is important for systematization of radiological and surgical anatomy in animals that serve as experimental models and in domestic animals. In veterinary and human medicine, information on the pattern of intestinal 
vasculature and its possible variations is essential since the gut can be affected by different pathologies that require rapid diagnosis and surgical intervention.

Among the visceral branches of the abdominal portion of the aorta, the celiac and mesenteric arteries have great relevance in clinical and surgical anatomy and angiographic procedures, because they are responsible for the irrigation of important viscera such as the liver, stomach, spleen, pancreas and gut (NAYAR, SINGH, SINGH et al., 1983).

In domestic animals, the cranial mesenteric artery arises in a unique way, caudally to the celiac artery, with which it forms in some cases a trunk called the celiacmesenteric trunk.

Nickel, Schummer and Seiferle (1983) report that the cranial mesenteric artery arises from the ventral surface of the abdominal aorta, immediately caudal to the celiac artery gives rise to the pancreatic branches (ruminants), the caudal pancreatic duodenal artery, jejunal arteries (with colic branches in small ruminants), collateral branches (bovines), ileal arteries, ileocolic artery - with colic branch (carnivores, pigs and equines), colic branches (ruminants), right colic arteries (ruminants), cecal artery (carnivores, pigs and ruminants), medial cecal artery (equines), lateral cecal artery (equines) and ileo-mesenteric branch, right colic artery and middle colic artery (equines).

According to Dyce, Sack and Wensing (2010) and König and Liebich (2011), the cranial mesenteric artery of the rabbit issues the middle colic artery, the caudal pancreatic duodenal artery, the right colic artery and one ileocolic branch. As for the caudal mesenteric artery, these authors allude to the fact that this vessel is divided into left colic arteries and cranial rectal artery, from which depart the sigmoid arteries.

Nayar, Singh, Singh et al. (1983) observed by arteriography the anatomy of the abdominal viscera and lower back in goats, carnivores, pigs and rabbits and reported that the cranial mesenteric artery in these species originates the following branches: the middle colic artery, which is the most developed branch and undergoes anastomosis with the left gastroepiploic artery; the ileocecocolic artery, which in goats and rabbits is the first branch issued; the cranial pancreatic duodenal artery; and numerous jejunal arteries that form anastomosis between them, creating arcs. The caudal mesenteric artery is a small vessel and divides into cranial and caudal branches.

The aim of this study was to describe the origin, esqueletopy and main branches of the cranial and caudal mesenteric arteries in rabbits, thus providing morphological data for comparative anatomy as well as surgical and experimental practice.

\section{Materials and Methods}

This study was performed with rabbit cadavers that had been sent to the animal anatomy area of Federal Rural University of Rio de Janeiro. They had been stored in a freezer since received.

Thirteen adult New Zealand rabbits ( 15 males and 15 females) were used. Initially the cadavers were thawed in running water, sexed and identified by placing numbered plastic tags attached with string to the common calcaneal tendon. A metal measuring tape was used to measure the rostro-sacral length of each animal, from the end of the snout to the tail set.

The cadavers were positioned in right lateral decubitus position for access to the thoracic portion of the aorta, through an incision made between the 6th and the 10th intercostal space. The artery was cannulated with a urethral catheter (number eight or ten, depending on the vessel diameter) and secured with string to prevent overflow and maintain intravascular pressure.

Fixation was done by caudally injecting a $10 \%$ formaldehyde solution through the catheter (variable volume depending on the cadaver's weight). Immediately after fixation of the cadavers Petrolátex S65 solution (Duque de Caxias Refinery, Petrobras, Duque de Caxias, RJ) mixed with Suvinil pigment was injected to fill the entire arterial system. Then each cadaver was immersed in a low density polyethylene cardboard box with capacity of 500 liters containing a 10\% formaldehyde solution to finalize the fixation and latex polymerization process.

Five days after latex injection, the cadavers were dissected to assess the origin and main branches of the cranial and caudal mesenteric arteries. The results were presented in schematic drawings relating to arterial organ systematization and photographed in situ. With the aid of a digital caliper, measurements in centimeters of the cranial and caudal mesenteric arteries (from origin to first branch) were obtained.

This publication is part of the project entitled "Systemic and Topographical Anatomy of the Rabbit: A study for surgical, radiological and experimental practice", which was approved by the research ethics committee of Federal Rural University of Rio de Janeiro (number 23083.002379/2007-08).

\subsection{Statistical analysis}

To check whether the distribution of observed frequencies for the 30 animals examined is consistent with the hypothesis, we applied the chi-square test $(\mathrm{X} 2)$ considering $\mathrm{P}<0.05$ as significant to test the null hypothesis, which relates to the origin of the cranial and caudal mesenteric arteries and number of core branches. In regards to the overall pattern of the mesenteric artery length as a function of rostro-sacral length, we chose to calculate the correlation coefficient " $r$ ", which can vary between -1 and +1 . The mean and standard deviation of the cranial and caudal mesenteric arteries' length were also calculated, and using the unpaired t-test these values were compared in both sexes.

\section{Results}

\subsection{Length}

The mean and standard deviation of the cranial mesenteric artery length in females was $2.63 \pm 0.565$ and $2.56 \pm 0.5104$ in males $(\mathrm{p}=0.7)$. The mean and standard deviation of the caudal mesenteric artery length in females was $0.78 \pm 0.48$ and $0.79 \pm 0.2261$ in males $(p=0.68)$. No relation was observed between the mesenteric artery length and the rostrum-sacral length in both sexes.

\subsection{Origin}

The cranial mesenteric artery emerged directly from the abdominal portion of the aorta as a single vessel in all dissected females and males. The caudal mesenteric artery originated directly from the aorta as a single artery in all dissected females and males.

\subsection{Esqueletopy}

In males the cranial mesenteric artery originated at the first lumbar vertebra in two cases (13.33\%), between the lst and 2 nd lumbar in two animals $(13.33 \%)$ in the 2 nd lumbar in 
eight (53.33\%) and between the 2 nd and 3 rd lumbar vertebra in three animals $(20 \%)$. In females, the origin occurred in the lst lumbar vertebra in two cases $(13.33 \%)$, between the lst and 2 nd lumbar in four animals $(26.67 \%)$, in the 2 nd lumbar in seven $(46.67 \%)$, between the 2 nd and 3 rd lumbar in one $(6.67 \%)$ in the $3 r d$ lumbar vertebra in one $(6.67 \%)$. Among all 30 animals (males and females), the source was in the lst lumbar vertebra in four animals $(13.33 \%)$, between the 1 st and 2 nd lumbar in six $(20 \%)$, the 2 nd lumbar in $15(50 \%)$, between the 2 nd and 3 rd lumbar in four (13.33\%), and in the 3rd lumbar vertebra in one animal $(3.33 \%)$.

The caudal mesenteric artery in the rabbits originated in the 5 th lumbar vertebra in two animals (13.33\%), between the 5 th and 6th lumbar one animal $(6.67 \%)$, in the 6th lumbar in seven $(46.67 \%)$, between the 6 th and 7 th lumbar vertebra in four $(26.67 \%)$ and in the 7 th lumbar vertebra in one animal $(6.67 \%)$. In females, it originated in the 5 th lumbar vertebra in three animals $(20 \%)$, between the 5 th and 6 th lumbar in two $(13.33 \%)$ in the 6 th lumbar in seven $(46.67 \%)$, between the 6th and 7th lumbar in two (13.33\%) and in the 7th lumbar in one animal $(6.67 \%)$. Among all 30 animals, the caudal mesenteric artery originated in the 5 th lumbar vertebra in five animals (16.67\%), between the 5th and 6th lumbar in three $(10 \%)$, in the 6th lumbar vertebra in 14 animals $(46.67 \%)$, between the 6th and 7 th lumbar in six animals $(20 \%)$, and in the 7 th lumbar in two animals $(6.67 \%)$.

\subsection{Main branches}

The main branches of the cranial mesenteric artery issued were: middle colic artery to the descending irrigated colon, forming anastomoses with the left colic artery; caudal pancreatic

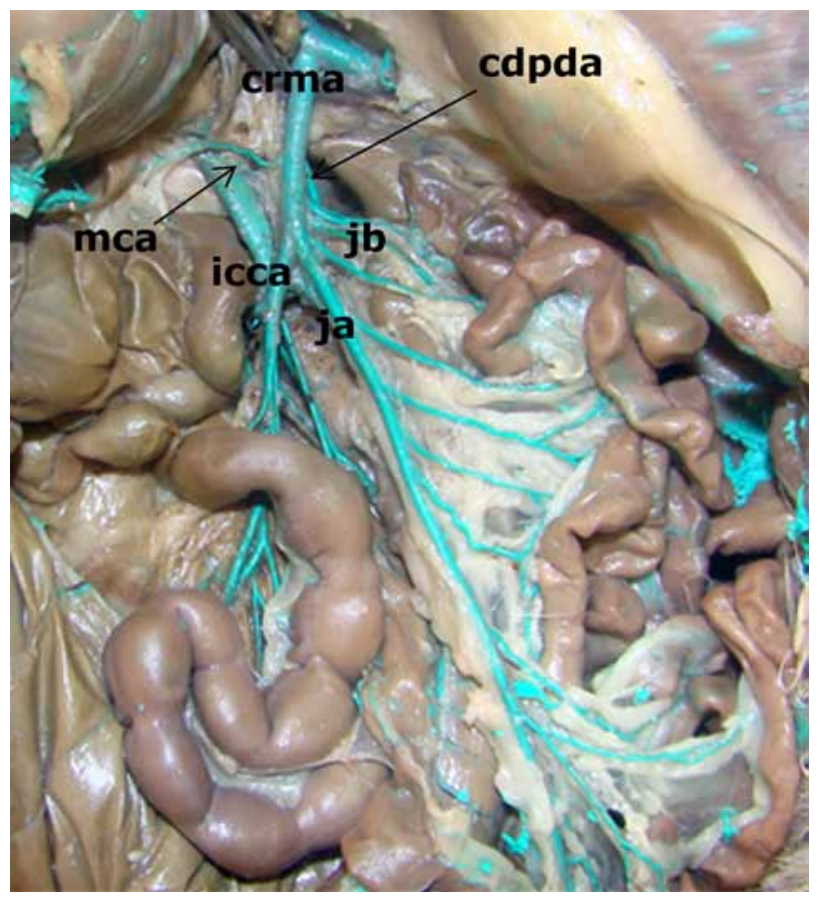

Figure 1. Photomacrography showing the main branches of the cranial mesenteric artery in rabbits. crma $=$ cranial mesenteric artery, mca $=$ middle colic artery, cdpda $=$ caudal pancreatic duodenal artery, icca $=$ ileocecocolic artery, ja $=$ jejunal artery, $\mathrm{jb}=$ jejunal branch. duodenal artery, which irrigated the caudal flexure of the duodenum and pancreas; jejunal artery, which distributes through the meso jejunum irrigating the jejunum and part of the cecum; and ileocecocolic artery, irrigating the ileum, cecum and ascending and transverse colon (Figure 1). The cranial mesenteric artery also issued small branches to the transverse colon and jejunal branches.

In males, the first branch issued was the middle colic artery in seven animals $(46.67 \%)$ and the caudal pancreatic duodenal artery in eight animals (53.33\%). The 2 nd branch issued was the middle colic artery in eight animals $(53.33 \%)$ and the caudal pancreatic duodenal artery in seven animals (46.67\%). The same was observed in females.

In males, the 3 rd branch issued was the jejunal branch in 12 animals $(80 \%)$ and the branch to the transverse colon in three $(20 \%)$. In females, the jejunal branch was the $3 \mathrm{rd}$ in 13 animals $(86.67 \%)$ and branched to the transverse colon in two cases $(13.33 \%)$.

Before the cranial mesenteric artery forks and gives rise to ileocecocolic and jejunal arteries, it sends branches to the transverse colon and jejunum. These jejunal branches are variable in number. A single jejunal branch was observed in four males (46.67\%) and one female $(6.67 \%)$, while two branches were observed in seven males and seven females (46.67\%), three branches in two males and two females (13.33\%).

The 4th branch issued in males was the jejunal branch in 12 animals (80\%) and the jejunal artery in three animals (20\%), while in females this was the jejunal branch in $12(80 \%)$ and branch to the transverse colon in three animals $(20 \%)$. The 5 th branch in males was the jejunal branch in seven animals (46.67\%), jejunal artery in six (40\%) and ileocecocolic artery in four $(26.67 \%)$. In females, the 5 th branch was the jejunal branch in eight animals $(53.33 \%)$, branch to the transverse colon in one animal $(6.67 \%)$ and jejunal artery in six animals (40\%).

The ileocecocolic artery, which was observed in all animals, issued the principal branches: branch to the transverse colon, a trunk that irrigates the vermiform appendix of the cecum, ileum and proximal loop of the ascending colon, branch to the central loop of the ascending colon and a trunk that irrigates

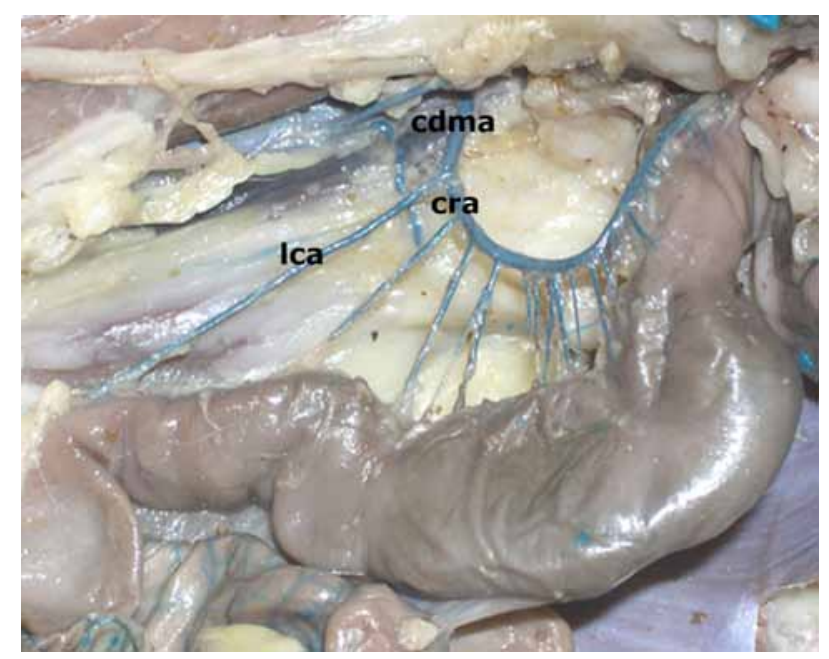

Figure 2. Photomacrography showing the main branches of the caudal mesenteric artery in rabbits. cdma $=$ caudal mesenteric artery, $\mathrm{lca}=$ left colic artery, $\mathrm{cra}=$ cranial rectal artery. 
the 1 st and 2 nd cecum gyrus and round saccule. Additionally, other smaller branches were also observed.

The jejunal artery was also observed in all animals in this study. The mean number of jejunal branches, considering the emitted jejunal artery branches and that observed earlier in the cranial mesenteric artery, was 17 in males and 18 branches in females.

In all study animals, the caudal mesenteric artery issued the left colic artery and cranial rectal artery (Figure 2 ). The left colic artery irrigated the entire descending colon, sending small branches to form anastomosis with the middle colic artery. The cranial rectal artery followed by descending top the meso colon and then entered the pelvic cavity and continued in the meso rectal direction, issuing numerous branches to irrigate the rectum.

\section{Discussion}

Typically, the celiac and cranial mesenteric arteries arise directly from the abdominal portion of the aorta as separate vessels, although they can have a common origin, or as reported by different authors, with the presence of a celiac-mesenteric trunk formed by the celiac and cranial mesenteric arteries. This variation has observed in sheep (LANCENFELD and PASTEA, 1977), buffalo (MACHADO, MIGLINO and CABRAL, 2000), goats (FERREIRA, MIGLINO, SILVA et al., 2001), zebu-crossed bovines (PEDUTI and SANTIS-PRADA, 1970), dogs (SCHMIDT and SCHOENAU, 2007), cats (ROZA, PESTANA, SILVA et al., 2009; ESTRUC, NASCIMENTO, GOMES et al., 2012) and humans (CAVDAR, SEHIRLI and PEKIN, 1997; ÇIÇEKCIBASI, UYSAL, ÔEKER et al., 2005). This arrangement was not observed in the rabbits dissected in the present study.

In cats dissected by Estruc, Nascimento, Gomes et al. (2012), the predominant presentation of the cranial mesenteric artery was as a single vessel ( 15 males and 13 females). In $90 \%$ of the rock cavies (Kerodon rupestris) studied by Queiroz, Moura, Lucena et al. (2011), the cranial mesenteric artery originated as an isolated branch of the abdominal aorta just after the origin of the celiac artery. Similar results were reported by Morais Lima, Souza-Rezende, Rocha et al. (2010) in a study conducted of the intestine of the crab-eating raccoon (Procyon cancrivorus), by Machado, Gonçalves, Parizzi et al. (2006) in nutrias (7 of 10 animals), and in New Zealand rabbits (MALINOVSKÝ and BEDNÁROVÁ, 1990; MACHADO, SOUZA, OLIVEIRA et al., 2008), corroborating the results obtained in the present study.

In $53.33 \%$ of male rabbits, the caudal pancreatic duodenal artery was the lst branch to emerge from the cranial mesenteric artery, while in $46.67 \%$ the lst branch was the middle colic artery. The same percentage was observed in females. Similarly, Estruc, Nascimento, Gomes et al. (2012) found in cats that the caudal pancreatic duodenal artery was the lst branch to emerge from the cranial mesenteric artery in $88.89 \%$ of males and $50 \%$ of females. This branch was also observed as the lst branch of the cranial mesenteric artery in $100 \%$ of New Zealand rabbits (MACHADO, SOUZA, OLIVEIRA et al., 2008), 60\% of nutrias (MACHADO, GONÇALVES, PARIZZI et al., 2006) and 25\% of rock cavies (QUEIROZ, MOURA, LUCENA et al., 2011).
The 2nd branch came from the middle colic artery in $53.33 \%$ of the rabbits or the caudal pancreatic duodenal artery in $46.67 \%$. The same was observed in females, corroborating the results obtained by Estruc, Nascimento, Gomes et al. (2012) in cats, where the middle colic artery appeared as a 2 nd branch of the cranial mesenteric artery in $83.33 \%$ of males and $57.14 \%$ of females, unlike Queiroz, Moura, Lucena et al. (2011), who found that in $75 \%$ of the rock cavies analyzed, the middle colic artery appeared as the 1st branch of the cranial mesenteric artery originated, similar to the results obtained by Atalar and Yilmaz (2005) of 78\% of the Hystrix cristata rodents studied and by Machado, Gonçalves, Parizzi et al. (2006) in 40\% of the nutrias analyzed.

In cats, Estruc, Nascimento, Gomes et al. (2012) showed the presence of jejunal artery as the 3rd branch emerging from the cranial mesenteric artery in $83.33 \%$ of males and $57.15 \%$ females, similar to that observed in the present study ( $80 \%$ of males and $8667 \%$ of females).

Queiroz, Moura, Lucena et al. (2011), in a study of rock cavies, observed that the duodenum jejunal artery was present in $95 \%$, with origin from the cranial mesenteric artery, immediately after the middle colic artery and caudal pancreatic duodenal artery, similar to that observed in $90 \%$ of the nutrias studied by Machado, Gonçalves, Parizzi et al. (2006). In the white-eared opossum, Pinto e Silva, Martins and Guazzeli-Filho (2008) observed that the jejunal artery comes from a common trunk and issues different branches (6-15), with anastomosis occurring between them.

In the present investigation, the 4 th branch to be issued in male rabbits was represented by jejunal branches $(80 \%)$ or the jejunal artery $(20 \%)$. In females, it was the jejunal branch $(80 \%)$ mor the branch to the transverse colon $(20 \%)$. In contrast, in cats Estruc, Nascimento, Gomes et al. (2012) observed that the 4th branch emerging from the cranial mesenteric artery was the ileocecocolic artery in $61.11 \%$ of males and $42.86 \%$ of females.

As 5 th branch in the male rabbits was observed in the jejunal branches $(46.67 \%)$, jejunal artery $(40 \%)$ or ileocecocolic artery $(6.67 \%)$. In females were the jejunal branches $53.33 \%$, branches to the transverse colon $6.67 \%$ or jejunal artery in $40 \%$. In a study of rock cavies (QUEIROZ, MOURA, LUCENA et al., 2011), the ileocecocolic trunk represented a continuation of the cranial mesenteric artery in $50 \%$ of the animals analyzed, similar to that observed by Atalar and Yilmaz (2005) in porcupines (Hystrix cristata). This arrangement was also mentioned by Nickel, Schummer and Seiferle (1983) as common in rodents. This trunk was also described by Figueiredo, Albuquerque and Souza (1979) in opossums and Albuquerque, Fernandes-Filho and Borelli (1976) in marmosets. Also in rock cavies, Queiroz, Moura, Lucena et al. (2011) observed that this trunk originated from the ileocecal and right colic arteries. However, in the nutria (MACHADO, GONÇALVES, PARIZZI et al., 2006) and in Hystrix cristata (ATALAR and YILMAZ, 2005), the right colic artery arose directly from the cranial mesenteric artery and anastomosis occurred with colic branch of the ileocolic artery.

In regard to the cranial mesenteric artery esqueletopy, Getty (1986) and Nickel, Schummer and Seiferle (1983) mentioned that in the dog the origin of the vessel occurs at the level of the 2nd lumbar vertebra and Evans and Cristensen (1993) reported that the origin of the vessel occurs between the lst 
and 2nd lumbar vertebra. Estruc, Nascimento, Gomes et al. (2012) observed that in cats the origin of the cranial mesenteric artery varied from the 1 st to the 4th lumbar vertebra. In this study, the cranial mesenteric artery in rabbits showed origin from the 1 s to the 3 rd lumbar vertebra, corroborating the results of Uddin, Rahman, Alam et al. (2012), who mentioned that in rabbits the origin occurs only at the level of the 2 nd lumbar vertebra.

In the rabbits dissected in the present investigation, the caudal mesenteric artery in females and males originated directly from the aorta as a single artery in $100 \%$ of the animals. These results agree with those obtained in New Zealand rabbits (MACHADO, SOUZA, OLIVEIRA et al., 2008), nutrias (MACHADO, GONÇALVES, PARIZZI et al., 2006), white-eared opossums (Didelphis albiventris) (PINTO E SILVA, MARTINS AND GUAZZELI-FILHO, 2008), rock cavies (QUEIROZ, MOURA, LUCENA et al., 2011) and cats (ESTRUC, NASCIMENTO, GOMES et al., 2012). However, Culau, Azambuja and Campos (2008), in a study of the visceral side branches of the abdominal aorta in Myocastor coypus (nutria) found that in $3.3 \%$ of the animals the caudal mesenteric artery was absent and his region was supplied by a well-developed branch of the cranial mesenteric artery, the left colic artery. This absence was also mentioned in cats (ESTRUC, NASCIMENTO, GOMES et al., 2012).

Santos-Júnior, Ferreira, Silva et al. (2005) reported that in German mastiff dog fetuses, the caudal mesenteric artery emerged from the ventral surface of the caudally descending abdominal aorta, near its termination, and after a short cranio-caudal trip issued the following branches: left colic artery by sending a series of colic branches, and cranial rectal artery, sending several colic and rectal arteries. These results are similar to those observed in this study.

In $100 \%$ of the rock cavies studied by Queiroz, Moura, Lucena et al. (2011), the caudal mesenteric artery issued as the main branches of the left colic and cranial rectal arteries. A similar pattern has been described in marmosets by Albuquerque, Fernandes-Filho and Borelli (1976), in opossums by Figueiredo, Albuquerque and Souza (1979), in white-eared opossums by Pinto e Silva, Martins and Guazzeli-Filho (2008), in agouties by Carvalho, Maglino, Didio et al. (1999), in nutrias by Machado, Gonçalves, Parizzi et al. (2006), in cats by Estruc, Nascimento, Gomes et al. (2012) and in rabbits (UDDIN, RAHMAN, ALAM et al., 2012), an arrangement also observed in the present study. The frequency with which the caudal mesenteric artery originates the left colic and rectal cranial arteries in the different species studied seems to indicate a similar pattern of vascularization for different species.

In regard to the caudal mesenteric artery esqueletopy, Getty (1986), Nickel, Schummer and Seiferle (1983) and Evans and Cristensen (1993) mentioned that in the dog the origin of this vessel occurs at the level of the 5th lumbar vertebra. Estruc, Nascimento, Gomes et al. (2012) observed that the origin of the caudal mesenteric artery varied from the 5 th lumbar vertebra to the lst sacral vertebra. In this study, the origin of the caudal mesenteric artery varied from the 5 th to 7th lumbar vertebra, corroborating the results of Uddin, Rahman, Alam et al. (2012), who mentioned that in rabbits the origin occurs only at the 6th lumbar vertebra.

From a more general point of view, any abdominal surgery that requires mobilization or hemostatic control of the cranial and caudal mesenteric arteries and their branches requires a systematic search for possible vascular anatomical variations. The complexity of these vascular changes can modify the technical possibilities of the surgical procedure, as well as those related to imaging diagnosis.

Sarathchandra, Lunn and Hunt (2009) reported the need for ligation of the caudal mesenteric artery in dogs during procedures of resection and anastomosis of the colon rectal junction in an annular adenocarcinoma, reinforcing the idea of the importance of knowledge of the vascular anatomy.

Esqueletopy, origin and branch variations of cranial and caudal mesenteric arteries in rabbits should be considered in the implementation of radiological, surgical and experimental procedures, aiming to avoid mistakes that are committed due to lack knowledge of the possible variations in these animals.

\section{Conclusion}

In conclusion, the cranial and caudal mesenteric arteries in rabbits have esqueletopy and varied ramifications in both sexes. No relationship between the mesenteric arteries lengths and the animal rostrum-sacral length was observed. The origin of the cranial and caudal mesenteric arteries is independent of sex.

Acknowledgements: We would like to thank Rio de Janeiro Research Foundation Support (FAPERJ) and National Council for Scientific and Technological Development (CNPq) for the financial source.

\section{References}

ALBUQUERQUE, JF., FERNANDES-FILHO, A. and BORELLI, V. Contribution to the study of branching of cranial and caudal mesenteric arteries in marmosets (Callithrix jacchus). Journal of the Faculty of Veterinary Medicine and Animal Science, 1976, vol. 13, p. 61-65.

AMORIM, MJ., AMORIM-JÚNIOR, AA., SILVA-JÚNIOR, VA., VILLAROUCO, FM., and HENRIQUE, VV. Total length from the intestine of mongrel rabbits (Oryctolagus cuniculus). Chilean Journal of Anatomy, 2002, vol. 20, p. 181-183.

ATALAR, O. and YILMAZ, S. The cranial mesenteric artery in the porcupine (Hystrix cristata). Veterinarski Arbiv, 2005, vol. 75, p. 75-82.

CARVALHO, MA., MIGLINO, MA., DIDIO, LJ. and MELO, AP. Cranial and caudal mesenteric arteries in agouti (Dasyprocta aguti). Veterinary News, 1999, vol. 2, p. 17-24.

CAVDAR, S., SEHIRLI, U. and PEKIN, B. Celiacomesenteric trunk. Clinical Anatomy (New York, N.Y.), 1997, vol. 10, p. 231-234.

ÇIÇEKCIBASI, AE., UYSAL, I., ÔEKER, M., TUNCER, I., BUYUKMUMCU, M. and SALBACAK, A. A rare variation of the coeliac trunk. Annals of Anatomy, 2005, vol. 187, p. 387-391.

CULAU, PO., AZAMBUJA, RC. and CAMPOS, R. Ramos colaterais viscerais da artéria aorta abdominal em Myocastor coypus (nutria). Acta Scientiae Veterinariae, 2008, vol. 36, p. 241-247.

DYCE, K.M., SACK, W.O. and WENSING, CG. Tratado de anatomia veterinária. 4th ed. Rio de Janeiro: Guanabara Koogan, 2010. 834 p.

ESTRUC, TM., NASCIMENTO, RM., GOMES, MS., MENCALHA, R. and ABIDU-FIGUEIREDO, M. Anatomical relationships between the origin and distribution of the cranial and caudal mesenteric arteries in the domestic cat. Brazilian Journal of Veterinary Medicine, 2012, vol. 34, p. 295-302.

EVANS, HE. and CRISTENSEN, GC. Anatomy of the dog. 2nd ed. Philadelphia: W. B. Saunders Company, 1993. 1112 p. 
FERREIRA, FA., MIGLINO, MA., SILVA, FO. and CARVALHO, FS. SANTOS, TC. Origins and ramifications of the cranial and caudal mesenteric arteries in Saanen goat fetuses (Capra hircus 3 / 4 Linnaeus, 1758). Brazilian Journal of Veterinary Research and Animal Science, 2001, vol. 38 , p. 69-73.

FIGUEIREDO, SF., ALBUQUERQUE, JF. and SOUZA, WM. Contribution to the study of branching of cranial and caudal mesenteric arteries in opossums (Didelphis aurita). Scientific Journal Faculty of Veterinary Science University of Zulia, 1979, vol. 7, p. 51-53.

GETTY, R. Sisson and Grossman's: anatomy of domestic animals. 5th ed. Rio de Janeiro: Interamericana, 1986. $1134 \mathrm{p}$.

KÖNIG, HE. and LIEBICH, HG. Anatomy of domestic animals: text and color atlas. 4th ed. Porto Alegre: Artmed, 2011. 787 p.

LANCENFELD, M. and PASTEA, E. Anatomical variants of the celiac artery in the sheep, with special reference to the celiomesenteric arterial trunk. Anatomischer Anzeiger, 1997, vol. 142, p. 168-174.

MALINOVSKY, L. and BEDNÁROVA, Z. Variability of ramification of the a. mesenterica cranialis in the domestic rabbit (Oryctolagus cuniculusf. domestica). Folia Morphologica, 1990, vol. 38, p. 283-292.

MACHADO, GV., GONÇALVES, PR., PARIZZI, A. and SOUZA, JR. Pattern of division and distribution of mesenteric arteries in nutria (Myocastor coypus, Rodentia: Mammalia). Biotemas, 2006, vol. 19 , p. 59-63.

MACHADO, MR., MIGLINO, MA. and CABRAL, VP. Origin of celiac and cranial mesenteric arteries in buffaloes (Bubalus bubalis). Brazilian Journal of Veterinary Research and Animal Science, 2000, vol. 37, p. 125-129.

MACHADO, MR., SOUZA, SV., OLIVEIRA, TC., CORTELLINI, LM. and BARBOSA, RR. Arterial supply of the New Zeland rabbit's intestines New Zealand (Oryctolagus cuniculus). Biotemas, 2008, vol. 21, p. 101-105.

MORAIS LIMA, V., SOUZA-REZENDE, AL. ROCHA, FJ. and PEREIRA, KF. Distribution of mesenteric cranial artery in the small intestine of Procyon cancrivorus (Cuvier, 1798) (Mammalia, Procyonidae). Acta Scientiarum. Biological Sciences, 2010, vol. 32, p. 175-179.

NAYAR, KN., SINGH, G., SINGH, Y. SINGH, AP. and SINGH, GR. Comparative arteriographic anatomy of the abdominal viscera and lumbar region in goats, dogs, pigs and rabbits. The Indian Journal of Animal Sciences, 1983, vol. 53, p. 1310-1314.
NICKEL, R., SCHUMMER, A. and SEIFERLE, E. The anatomy of the domestic animals. 1st ed. Berlin: Verlag Paul Parey, 1983. 610 p.

PEDUTI, NJ. and SANTIS-PRADA, IL. Origin of the celiac and cranial mesenteric arteries by common trunk, in fetuses of zebucrossed bovines. Journal of the Faculty of Veterinary Medicine of São Paulo, 1970, vol. 8, p. 399-402.

PINTO E SILVA CJ., MARTINS, MR., GUAZZELI-FILHO, J. Study on cranial and caudal mesenteric arteries in opossum (Didelphis albiventris). International Journal of Morphology, 2008, vol. 26, p. 635-637.

QUEIROZ, PV., MOURA, CE., LUCENA, JA. and OLIVEIRA, MF. ALBUQUERQUE, JF. Cranial and caudal mesenteric arteries in rock cavies Kerodon rupestris (Wied, 1820). Brazilian Veterinary Research, 2011, vol. 31, p. 623-626.

ROZA, MS., PESTANA, FM., SILVA, BX., HERNANDEZ, JM. and ABIDU-FIGUEIREDO, M. Mesenteric celiac trunk in Cat. Portuguese Journal of Veterinary Science, 2009, vol. 10, p. 83-86.

SANTOS-JUNIOR, MJ., FERREIRA, FA., SILVA, FO. and LIMA, EM. Origins and ramifications of the cranial and caudal mesenteric arteries in canine German mastiff. Scientific horizon, 2005, vol. 1, p. 1-9.

SARATHCHANDRA, SK., LUNN, JA. and HUNT, GB. Ligation of the caudal mesenteric artery during resection and anastomosis of the colorectal junction for annular adenocarcinoma in two dogs. Australian Veterinary Journal, 2009, vol. 87, p. 356-359.

SCHMIDT, DP. SCHOENAU, LS. Origin of the celiac and cranial mesenteric arteries by common trunk in dog. Rural Science, 2007, vol. 37, p. 408-411.

UDDIN, M., RAHMAN, ML. and ALAM, MA. AHASAN, AS. Anatomical study on origin, course and distribution of cranial and caudal mesenteric arteries in the White New Zealand rabbit (Orycotolagus cuniculus). International Journal of Natural Sciences, 2012, vol. 2, p. 54-59.
Received October 15, 2014

Accepted November 18, 2015 